\title{
La presencia de mercenarios extranjeros en Castilla durante la primera mitad del siglo xv: la intervención de Rodrigo de Villandrando, Conde de Ribadeo, en 1439
}

Fernando Castillo Cáceres

Al contrario de lo sucedido en el siglo XIV ${ }^{1}$, la participación de tropas extranjeras en las diferentes fases de la guerra civil castellana que durante la primera mitad del siglo XV enfrentó a la monarquia y a la oligarquía nobiliaria, fue un acontecimiento excepcional ${ }^{2}$. Quizás fuera, como afirma Ladero Quesada ${ }^{3}$, porque carecía de sentido acudir a la contratación de

1 Acerca de la intervención militar extranjera en Castilla durante el siglo xIV se pueden consultar: Benito Rodriguez, Miguel Ángel de, "Las tropas extranjeras y su participación en los ejércitos castellanos durante la Baja Edad Media", Revista de Historia Militar, n. ${ }^{\circ} 75,1993$, pp. 47-75. CASTILlo CÁCERES, Fernando, "Análisis de una batalla: Nájera (1367)", en Cuadernos de Historia de España, n. ${ }^{\circ}$ LXXIII, 1991, pp. 107-146. FowLER, Kenneth, "L'emploi des mercenaires par les pouvoirs iberiques et l'intervention militaire anglais en Espagne (vers 1361-vers 1379)", en Realidad e imágenes del poder. España a finales de la Edad Media, coord. de Adeline Rucquoi, Salamanca, 1988, pp. 23-56. "The wages of War. The Mercenaires of the Great Companies", en XVII Semana de Estudios Medievales, Estella, 1991, LADERO QUESADA, Miguel Ángel, "La organización militar de la Corona de Castilla en la Baja Edad Media", en Castillos Medievales del Reino de León, s.a. y s.I., pp. 11-34. RusEL..., P.E.: The English Intervention in Spain and Portugal in the Time of Edward III and Richard II, Oxford, 1955. VALDEÓN BARUQUE, Julio, "La guerra civil castellana. Intervenciones extranjeras en el marco de la guerra de los Cien años", Cuademos de Historia 16, n. ${ }^{\circ}$ 150, Madrid, 1985.

2 Hay en el siglo XV una presencia de jinetes granadinos al servicio del rey e incluso de algún noble como Rodrigo Manrique. Por su parte, la Refundición del Halconero (edición de Juan de Mata Carriazo, Madrid, 1946) alude a los caballeros moros capitaneados por Abenamar que piden en 1436 a Juan II licencia para irse a Túnez (cap. CXVI, p. 206). También durante la guerra civil mantenida entre Enrique IV y Alfonso de Ávila hubo negociaciones para intentar obtener apoyo del conde Foix y del rey Alfonso $V$ de Portugal que no se concretó. (Benito Rodriguez, ob. cit., pp. 6667. Morales Muñz, Dolores Carmen, Alfonso de Ávila, rey de Castilla, Ávila, 1988, p. 147). Sobre la presencia individual de caballeros en Castilla, ver ANTELo IGLESIAS, Antonio, "Caballeros centroeuropeos en España y Portugal durante el siglo XV". Espacio, tiempo y forma, III-1, 1988, pp. 45-58.

3 Ladero Quesada, ob. cit., pp. 27-28. 
contingentes extranjeros dado el carácter mixto de obligación y mercenariado local que tenían las milicias concejiles en el Cuatrocientos; o porque el signo de la guerra civil castellana fuera una constante negociación, sin apenas enfrentamientos y estos, cuando se producían, eran muy poco sangrientos ${ }^{4}$, algo por otra parte caracteristico de la Edad Media ${ }^{5}$. La realidad es que la intervención de tropas extranjeras en el conflicto interno desarrollado en la primera mitad del siglo $\mathrm{xV}$, fue un acontecimiento tan sumamente singular que queda reducido a la participación de Rodrigo de Villandrando, conde de Ribadeo, en los sucesos de 1439. Este famoso capitán de compañías, que había tenido una destacada participación en la Guerra de los Cien Años al servicio de Carlos VII de Francia, adquiriendo reputación de valeroso y cruel ${ }^{6}$, intervino a requerimiento de Juan II en el conflicto que enfrentaba a los principales linajes señoriales, encabezados por el Almirante Fadrique Enríquez y el Adelantado Pedro Manrique, con el monarca y el Condestable Álvaro de Luna. Aunque las crónicas de la época y algunos de los trabajos generales sobre el periodo en cuestión mencionan la intervención del conde de Ribadeo y el choque acaecido en Roa entre las tropas nobiliarias y los mercenarios franceses ${ }^{7}$, ni estas obras, ni las dedicadas a la historia militar del período conceden importancia o ni siquiera recogen este acontecimiento, cuya relevancia creemos es superior a lo que aparenta ${ }^{8}$. Esta circunstancia, junto al creciente

4 SuÁrez Fernández, Nobleza y Monarquia, Valladolid, 1975, p. 148.

5 En relación con la guerra y el arte militar de este periodo, se pueden consultar entre otros los trabajos de Charles W.C. OMAN, The Art of War in the Middle Ages A.D. 378-1515, London, 1984 (ed. de John H. Beeler), Hans DelBruck, History of the Art of War. Within the Framework of Political History, Volumen III. The Middle Ages, Wesport, 1975, Archer JoNEs, The Art of War in the Western World, New York, 1989. Ferdinand LOT, L'Art Militaire et les Armees au Moyen Age en Europe et le Proche Orient, Paris, 1946. Gaston Bouthoul, Tratado de Polemologia, Madrid, 1984. Phillippe Contamine, La guerra en la Edad Media, Barcelona, 1984.

6 Sobre Rodrigo de Villandrando, conde de Ribadeo, existen los siguientes títulos: Antonio María FABIE, Don Rodrigo de Villandrando, conde de Ribadeo, Madrid, 1882, Jules QUICHERAT, Rodrique de Villandrando, l'un des combattants por l'independance française au quinzième siècle, París, 1879, José Manuel CALDERÓN ORTEGA, "La formación del señorío castellano y el mayorazgo de Rodrigo de Villandrando, conde de Ribadeo (1439-1448)", Anuario de Estudios Medievales, XVI, 1986, pp. 421-447. "La evolución histórica del castillo de Garci Muñoz durante la primera mitad del siglo XV: el señorío de la villa por Rodrigo de Villandrando, conde de Ribadeo", Congreso de Historia del Señorío de Villena, Albacete, 1987, Fernando del PuLgar, Claros varones de Castiila, Madrid, 1942, (Clásicos Castellanos), pp. 62-71.

7 SuÁrez Fernández, Luis, Los Trastámara de Castilla y Aragón en el siglo xv chistoria de España" dirigida por Ramón Menéndez Pidal, XV, Madrid, 1970, p. 157. PÉREZ DE GuzMÁn, Fernán, Crónica de Juan II, (ed. BAE), Madrid, 1953, p. 556. Carrillo de Huete, Pedro, Crónica del Halconero de Juan II, ed. de Juan de Mata Carriazo, Madrid, 1946, p. 293. Porras Arboledas, Pedro A., Juan II (1406-1454), Palencia, 1995, p. 207 y ss.

\& TORRES GaRCia, "La guerra en Castilla durante la primera mitad del siglo xv: Las campañas de D. Álvaro de Luna a través de las crónicas", Revista de Historia Militar, 63, 1987, pp. 11-35. Benito Rodriguez, ob. cit., Fowler, ob. cit., ... 
interés existente por las cuestiones relacionadas con el arte de la guerra en la Edad Media y la reciente publicación uno de los escasos trabajos dedicados al ejército y la guerra durante la época Trastamara ${ }^{9}$, me han animado a la realización de estas páginas.

La intervención en el conflicto que afectaba a Castilla de las compañías de mercenarios formadas en Francia, donde eran famosas y temidas bajo el nombre de écorcheurs, por Rodrigo de Villandrando, uno de los populares routiers de la época, aunque fue muy reducida en el tiempo y en el espacio - pues sólo estuvieron en suelo castellano tres meses y no salieron de Roa- tuvo gran importancia ${ }^{10}$. En primer lugar, hay que señalar que la llegada de estos mercenarios supone continuar con la tradición de la llamada a tropas extranjeras que tanto desarrollo adquirió en el siglo xIV. Por otra parte, la intervención de Villandrando desequilibró la relación de fuerzas existentes y precipitó los acontecimientos acelerando la resolución del conflicto. La venida de estas fuerzas dio lugar a las primeras maniobras de carácter militar y al único episodio que tuvo verdadero contenido bélico de esta fase de la guerra civil, en el que se demostró la superioridad de estas unidades extranjeras - compuestas de arqueros y ballesteros montados, junto a la tradicional caballería pesada, los hombres de armas- y el respeto que hacia ella sentían sus adversarios. Por último, señalar que la escaramuza ocurrida en Roa en junio de 1439 y la presencia en la ciudad de los tres mil mercenarios íranceses a las órdenes de Villandrando, provocó que Juan de Navarra abandonase su actitud de equívoca neutralidad y el papel de mediador y se inclinara decididamente hacia el bando nobiliario, lo que supuso la derrota de Álvaro de Luna.

En agosto de 1437 se produce el final de la colaboración que mantenían desde 1430 la oligarquía nobiliaria castellana y el Condestable, cuyo resultado más reseñable fue conseguir alejar de la vida política castellana a los infantes de Aragón. En aquella fecha, Álvaro de Luna había decidido acabar con la creciente oposición señorial recurriendo a la fuerza ${ }^{11}$. La maniobra pretendía descabezar el movimiento antilunista y aunque logró

9 Benito Rodríguez, Miguel Ángel de, “Estructura y organización del ejército Trastámara. Aproximación a la Historia Militar castellana en la Baja Edad Media", Revista de Historia Militar, 78,1995 , pp. 13-40. Este trabajo forma parte de la memoria de licenciatura (inédita) del mismo autor La guerra en Castilla durante el periodo Trastámara (1966-1980), Universidad Autónoma de Madrid, 1993.

10 En ese sentido se manifiesta QuICHERAT en las páginas dedicadas a glosar la presencia del Conde de Ribadeo en Castilla.

11 Sobre los acontecimientos políticos del período: SuÁrez FERnÁndez, Nobleza... y Los Trastámara..., PoRRas ARBOledas, ob. cit. 
encarcelar al Adelantado Pedro Manrique, el Almirante Enríquez logró escapar y refugiarse en sus estados de Tierra de Campos e iniciar lo que constituiria la primera fase de la rebelión nobiliaria. La fuga de Pedro Manrique en agosto de 1438 confirmó el fracaso del acto de fuerza del Condestable y supuso la extensión del movimiento. La gravedad que iban tomando los acontecimientos y las continuas deserciones de nobles fieles a don Álvaro permitían aventurar la inminencia del recurso a las armas por ambas partes. La rapidez con que se extendía la sublevación de los grandes en los últimos meses de 1438 y el estado de guerra abierta entre ambos bandos, se pone de manifiesto en los contactos que mantienen Juan II y Álvaro de Luna con Rodrigo de Villandrando, a la sazón vagando por la región de Toulouse al frente de sus compañías, sin ocupación tras la paz de Arrás y la reconciliación franco-borgoñona ${ }^{12}$. Villandrando se había convertido en conde de Ribadeo en 1431 gracias a los servicios prestados a la causa de Juan II durante la guerra con Aragón en 1429-30, así como al gran prestigio militar adquirido a lo largo de la guerra en Francia y a la intervención personal de Carlos VII, deseoso de conseguir para su capitán fuera de su reino las recompensas que no estaba dispuesto a concederle ${ }^{13}$. Este routier no disfrutaba en el país vecino de un rango social semejante al que gozaba en Castilla a causa de su condición de extranjero y de jefe de una banda de mercenarios ${ }^{14}$, quienes, a pesar de su indiscutible valor en cuestiones militares, tenían una escasa consideración en una Corte definida por las reglas de la caballeria, las cuales imponian otros métodos de combate aunque menos eficaces, más vistosos. No se puede afirmar que para Villandrando, como para otros muchos caballeros sin fortuna como Pero Niño ${ }^{15}$, la guerra no fuera un eficaz instrumento de ascenso social ya que consiguió grandes riquezas y favores al servicio de Carlos VII y, sobre todo, ingresar en la oligarquía nobiliaria castellana, pero no logró alcanzar en Francia una consideración equiparable. Esta circunstancia, junto a su participación en una conjura contra los ministros de Carlos VII, Richemont y Carlos de Anjou, y el citado fin de las hostilidades, hicieron patente lo incómodo de su situación y aconsejaron su traslado hacia la zona del Languedoc, dónde se dedicó a vivir sobre el terreno durante gran parte

QUICHERAT, ob. cit., pp. 163 y ss.

Fabie, ob. cit., pp. 13, 59 y 61. Calderón Ortega, “La formación ...", p. 438.

CALDERÓN ORTEGa, “La formación...., p. 422.

15 Sobre caballeros españoles por Europa en ésta época ver RIQueR, Martín de, Caballeros andantes españoles, Madrid, 1967, quien menciona a Rodrigo de Villandrando y sus hazañas en Francia (pp. 140 y ss.). 
de $1438^{16}$. Las gestiones iniciadas en octubre de este año por Álvaro de Luna, encaminadas a contar con el concurso de las experimentadas fuerzas del conde de Ribadeo, revelan la voluntad del Condestable y de Juan II de acabar con el conflicto que les enfrentaba con la oposición señorial recurriendo a las armas, algo que no impedía se continuara manteniendo contacto con los rebeldes, a los cuales se concedió una serie de garantías ${ }^{17}$. No obstante, en la carta que Juan II dirige el 6 de noviembre de 1438 a Fernán Sánchez de Tovar ${ }^{18}$, sobrino de Rodrigo de Villandrando, con las instrucciones que ha de comunicarle, se alude a un ofrecimiento previo del conde de Ribadeo en el que parece incluso que se detallaba el tipo y la cantidad de las tropas con que este debería acudir a Castilla al referirse a aquellas gentes que m'enbio ofrecer. Esta oferta del routier, la cual se debió producir al fugarse Pedro Manrique y generalizarse la rebelión de los grandes, probablemente obedecia a su temor a perder las mercedes recibidas del rey en 1431 y $1435^{19}$, aunque no disminuye en absoluto el interés demostrado por el Condestable y el propio Juan II por atraerse las experimentadas fuerzas del famoso jefe de compañía. Como señala el propio Fabié ${ }^{20}$, la carta de Juan II de 6 de noviembre de 1438 debió escribirse en un momento en el que parecía que las conversaciones iniciadas con los señores alzados podían arrojar un resultado positivo para la causa del partido monárquico y quedar controlada la rebelión. Así se entienden las instrucciones que el rey envía a Villandrando, recomendándole una actividad expectante a la espera de acontecimientos. Esta prudente medida responde no sólo a razones políticas sino también a evitar la contratación de unas tropas cuyos servicios eran caros y su presencia en el reino un riesgo ${ }^{21}$. No obstante, en la misma carta se percibe

16 Perroy, Edward, La Guerra de los Cien Años, Madrid, 1982. En esta obra las referencias a Villandrando son abundantes.

17 Este es un ejemplo más de la habilidad y ductilidad política que ha permitido referirse a Álvaro de Luna como un prototipo temprano de gobernante maquiavélico (CAMILLO, Ottavio di, El humanismo castellano del siglo xv, Valencia, 1976, p. 179).

18 FABIE, ob. cit., apéndice XII, pp, 222-223. Tanto esta carta como la enviada al conde de Ribadeo directamente (apéndice $X \mathrm{X}$ ), proceden según este autor del archivo de los condes de Salinas y Ribadeo, las cuales hoy día están perdidas (CALDERón, "La formación...", p. 423, notas 17 y 18).

19 SuÁrez Fernández, Nobleza..., p. 150.

20 FABIE, ob. cit, p. 106.

21 Los estragos cometidos por los mercenarios fueron siempre un riesgo. En 1366 las compañías francesas al servicio de Carlos $V$ vagaban por el sur de Francia llevando a cabo numerosos pillajes, to que dio lugar a que el propio monarca francés, Pedro IV de Aragón y el Papa Urbano $\mathrm{V}$, a la sazón en Aviñón, financiaran su contratación por Enrique de Trastámara para librarse de su presencia. (CASTILlo CACERES, ob. cit., p. 110). Sobre los efectos del paso de estos soldados tenemos un ejemplo en AzcáaAte Aguilar-Amat, Pilar, "El azote de las Compañías y sus 
la elevada consideración que tenía Juan II del conde de Ribadeo, la familiaridad del trato que le otorgaba así como lo adelantado que estaban los contactos, pues se alude de forma explícita a la solicitud de la concesión de la Orden de la Banda para algunos lugartenientes del routier, a las que el rey accede. Por último, este documento muestra la importancia que se concedia al apoyo de Villandrando en la seguridad de que la eficacia y pericia de estas fuerzas desequilibrarian la relación de fuerzas existentes en el reino en favor de Juan II y Álvaro de Luna.

La contratación de tropas asalariadas durante la Edad Media e incluso la Antigüedad, responde a una serie de razones en las que prácticamente todos los autores coinciden. Sin embargo, es necesario acudir previamente a la definición de mercenario que recoge Contamine, el cual según este autor debe reunir la triple condición de especialista, apátrida y estipendiado ${ }^{22}$, para entender mejor las razones que impulsan a recurrir a estos combatientes, pues estos motivos se resumen en las citadas caracteristicas, como más adelante veremos. Otro requisito inicial que hay que tener presente es el carácter excepcional que reviste habitualmente el alquiler de las compañías de mercenarios y la urgente necesidad de su apoyo que suele tener el contratante ${ }^{23}$, dos aspectos que se cumplen con ocasión de la intervención de Villandrando, ya que esta era la primera ocasión que durante el reinado de Juan II están presente fuerzas mercenarias extranjeras al servicio del rey. Por otra parte, la llamada a estas tropas coincide con uno de los momentos más críticos por los que atravesaron Álvaro de Luna y Juan $I I$ en su enfrentamiento con la oligarquia nobiliaria. A este respecto hay que señalar que la extensión de la rebelión y la desafección de la nobleza fue tan intensa que debió privar al rey del concurso de gran parte de las huestes señoriales ${ }^{24}$, las cuales constituían uno de los elementos fundamentales de los que componen el heterogeneo Ejército real ${ }^{25}$, al que tenían que acudir los señores al llamado del monarca ${ }^{26}$. Esta obligación

estragos en Navarra (1366-1367), Hispania, n. ${ }^{\circ} 177,1991, \mathrm{pp} .73-101$. Por su parte, el paso de los ejércitos es un motivo de temor ancestral en Europa cuyo origen se remonta a esta época con toda probabilidad. Ver Jean Delumeau, El miedo en Occidente, Madrid, 1989, p. 246.

22 CONTAMINE, ob. cit., p. 125.

23 BENITO RODRIGUEZ, "Las tropas extranjeras..." p. 47.

24 Un ejemplo de cómo estas deserciones afectaron directamente a los contingentes nobiliarios al servicio del partido realista se registra en febrero de 1439, cuando una serie de señores que tenian acostamiento con el Condestable, al finalizar este se pasan inmediatamente al servicio del Almirante Enriquez (PorRas ARBoledas, ob. cit., p. 205).

${ }_{25}$ GrASSOTT, Hilda, "Organización política administrativa y feudovasallatica de León y Castilla durante los siglos XI y XII", en Los reinos cristianos en los siglos XI y XII. Economias, Sociedades $e$ Instituciones, Historia de España, Ramón Menéndez Pidal, Madrid, 1992, Tomo X, vol. 2, p. 164.

${ }_{26}$ Ladero Quesada, ob. cit., p. 19 y ss. Benito Rodríguez “Estructura...", p. 18 y ss. 
de llevar a la hueste real un número determinado de caballeros y a no retirarlos hasta que el rey lo ordenase, era una temprana exigencia a todos los magnates que habían recibido alguna recompensa del monarca ${ }^{27}$. Teniendo en cuenta todo ello, es fácil entender que la falta de apoyo por causas políticas o sociales de sectores vitales para el mantenimiento de la estructura militar, llevase a recurrir a contingentes de mercenarios ${ }^{28}$. Otro factor que suele aconsejar acudir a estos combatientes es la posibilidad de disponer de fuerzas militares de forma permanente, sin estar sujeto el contratante a plazos previamente estipulados o a la duración de la campaña. Esta cuestión resulta especialmente importante si tenemos en cuenta el tipo de conflicto que representa la guerra civil castellana, la cual, como veremos, se alarga en el tiempo sin buscar ni el choque frontal ni objetivos de carácter militar. Paralelamente, cada vez era más acuciante la necesidad que tenían los contendientes de contar con importantes efectivos militares para afrontar las interminables negociaciones en condiciones ventajosas y emprender iniciativas políticas que consolidasen sus respectivas posiciones. Ante esta situación, en la cual la disponibilidad de fuerzas era una evidente exigencia, el Ejército real contaba con unos exiguos contingentes de carácter permanente, los guardas reales, que Ladero denomina el pequeño ejército real fijo de Álvaro de Luna ${ }^{29}$, aludiendo a su creador, siendo el resto vasallos del rey que acudían a su llamada y con los que se podían establecer contratos de acostamiento ${ }^{30}$. Es indudable que la

27 GRASSOTTI, ob. cit., p. 164.

28 CONTAMINE, ob. cit., p. 126.

29 LADERO QUESADA, ob. cit., p. 32.

30 Sobre el ejército castellano de la época se puede acudir, entre otros trabajos, a los de LADERo Quesada, Miguel Ángel, ob. cit., y Castilla y la conquista del reino de Granada, Granada, 1987, Benito Rodriguez, "Estructura...". Redondo Diaz, Fernando, Historia del Ejército español 2, los ejércitos de la Reconquista. Mitre, Emilio, "La guerra de la Edad Media", Cuadernos de Historia 16, 206, Madrid, 1985, Moxó, Salvador de, "Ejército óplomacia y finanzas como medios de acción del Estado en la Baja Edad Media», Studium, 7-8, 1959, pp. 85-104. Grassortl, Hilda, ob. cit., ClonARD, Conde, (José M. ${ }^{a}$ de Soto). Historia orgánica de las armas de infantería y caballeria españolas desde la creación del ejército permanente hasta el dia. Madrid 1851-59, BARADO, Francisco, Museo Militar (Historia, indumentaria, armas, sistemas de combate, institución organización del ejército español). Barcelona, 1886. MoRALES Muñız, Dolores Carmen, Alonso de Quintanilla, un asturiano en la Corte de los Reyes Católicos, Madrid, 1993, especialmente el capítulo Ill, 2. a parte. SOLER DEL CAMPO, Álvaro, El armamento medieval hispano, Madrid, 1987. ARANTEGUI Y SANZ, J., Apuntes históricos sobre la artillería española en los siglos XIV y XV, Madrid, 1897. VIGÓN SUERODiaz, Jorge, Historia de la artillería española, Madrid, 1947, y El Ejército de los Reyes Católicos, Madrid, 1963. Lanuza Cano, Francisco, El ejército en tiempo de los Reyes Católicos, Madrid, 1953, SOtTo y Montes, José de, “Organización militar de los Reyes Católicos (1474-1517), Revista de Historia Militar, n. ${ }^{\circ} 14,1963$. BATISTA GonzÁleZ, Juan "Los combatientes y los modos militares bajo medievales", en Los reinos hispánicos ante la Edad Moderna, Madrid, 1992, pp. 509-538. También es útil, a pesar de no coincidir con la época, el trabajo de Francisco GARCIA FITZ, "La didáctica militar en la literatura castellana (segunda mitad del siglo XIı y primera del XIV)", Anuario de Estudios Medievales, 19, 1989, pp, 271-283. 
existencia de este tipo de relación militar y el carácter mixto de obligación y de casi mercenariado local que poseian en el siglo xv las milicias concejiles ${ }^{31}$, no hacian tan acuciante el recurso a los mercenarios como en el siglo XIV ni era tan valorada su disponibilidad, pues el Ejército real se nutria de estas fuerzas sin excesivos problemas. Otra cosa era cuando, por las razones señaladas anteriormente por Contamine, esta posibilidad disminuye o desaparece, bien cuando se necesitaba prolongar el período de disponibilidad de las tropas o cuando éstas estaban en inferioridad manifiesta. Es necesario detenerse en las diferencias existentes entre las fuerzas que componian el ejército castellano para poder entender mejor las razones que impulsan a la contratación de las tropas extranjeras. Aunque todos los contingentes que componian el Ejército real estaban retribuidos por su concurso, tanto la llamada a los vasallos a soldada, el establecimiento de contratos de acostamientos como el recurso a las milicias concejiles implicaban una relación previa, un vínculo jurídico entre ambas partes, -el rey en este caso, y el señor o los concejos-, que permite la prestación del servicio y da lugar a unas situaciones que rebasan lo establecido y derivado de una mera asociación retribuida ${ }^{32}$. Un ejemplo de esta particular relación lo constituyen las limitaciones que tienen aquellos que están sujetos a un contrato de acostamiento para servir a otro señor, pues para ello necesitan el consentimiento previo del actual ${ }^{33}$. Por el contrario, los mercenarios extranjeros no necesitaban ninguna autorización para pasar al servicio de quien les contrataba, ni tampoco era necesaria la existencia o el establecimiento de vínculos jurídicos de algún tipo para alquilar sus armas. La vinculación en este caso estaba definida de forma exclusiva por el elemento económico, es decir, que la contratación se aseguraba, al igual que el mantenimiento de los servicios militares, mediante el pago y el cumplimiento de los compromisos estipulados, sin necesidad de relación previa alguna. De acuerdo con lo anterior, la conexión establecida entre Juan II y Rodrigo de Villandrando puede resultar difícil de encuadrar en los diferentes tipos a que hemos aludido, pues a pesar de que este capitaneara unas compañías mercenarias, creadas y reclutadas en Francia, su condición de conde de Ribadeo suponía la existencia de una relación jurídica previa con Juan II de tipo vasallático que permitía el establecimiento de un contrato de acostamiento o de cualquier otra relación de carácter militar que pudiera derivarse de esta vinculación jurídica

LADERO QUESADA, "La organización...", p. 27.

GRASSOTTI, ob. cit., pp. 161 y sS.

BENITO RODRIGUEZ, "Las tropas...", p. 51. Hay que señalar que la complejidad que tiene la cuestión de los acostamientos contrasta con la falta de una monografia que se ocupe del asunto. 
con el rey de Castilla. Precisamente este aspecto contribuye a explicar, más allá del natural temor por su posible desafección, las continuas alusiones que realiza Juan II a Rodrigo de Villandrando, apelando a su lealtad y caballerosidad para que continúe a su servicio, al tiempo que se proclama su Rey e señor natural ${ }^{34}$. Las mercedes y concesiones otorgadas por el monarca al conde de Ribadeo una vez finalizada la intervención de los franceses, como la villa de Garcí Muñoz y el alfolí de la sal de Ribadeo entre otros favores ${ }^{35}$, lo fueron en pago por los servicios prestados y en cumplimiento de la promesa, reiteradamente realizada, de recompensarle ${ }^{36}$. Parece, por tanto, que Villandrando pudo acudir al servicio de Juan II como conde de Ribadeo, mediante alguna modalidad de acostamiento que garantizase su retribución o bien como vasallo a soldada, antes que como capitán de mercenarios asalariado ${ }^{37}$. De acuerdo con esta relación, el routier recibiria a cambio de los servicios de sus écorcheurs y de su propia participación una serie de mercedes del rey que consolidarian su posición y linaje en Castilla, sobre todo una vez que había dado por finalizada su experiencia francesa. Da la impresión que el ejemplo de Beltrán Du Guesclin y Pierre de Villaines, quien precisamente fue el primer conde de Ribadeo ${ }^{38}$, debió guiar a Villandrando para consumar mediante sus servicios su integración en los grandes linajes castellanos.

En lo que se refiere al coste y al pago de las compañias de mercenarios que acuden a Castilla con Villandrando, encontramos en un documento citado por Calderón Ortega ${ }^{39}$ referencias a la merced de cien mil maravedies de juro hecha por Juan II al conde de Ribadeo, en satisfacción

34 FABIE, ob. cit, apéndice XIV.

35 Calderón Ortega, "La formación...", p. 425.

36 Ver la carta de Juan Il dirigida al conde de Ribadeo, techada en Medina el 30 de junio de 1439. (FABIE, ob. cit, apéndice XIV).

37 Ya hemos señalado la obligación que contraian aquellos nobles que recibian del monarca alguna recompensa en tierra y soldadas, de lievar a la hueste real a un determinado numero de caballeros y no retirarlos hasta que el rey lo ordenase (GRASSOTTI, ob. cit., p. 164).

38 Esta villa convertida en condado fue concedida como recompensa a Pierre de Villaines por Enrique II en 1369, tras su triunfo en la guerra civil, por los servicios prestados durante la misma. Los mercenarios que sirvieron bajo las banderas del Trastámara y sobre todo aquellos que estuvieron junto a él en Nájera en 1367, fueron generosamente retribuidos cuando llegó al trono. Entre todos destaca Beltrán Du Guesclin, quien recibió 120.000 doblas, el titulo de duque de Molina y los señorios de Soria, Almazan, Deza, Atienza, Serón y Monteagudo. Por su parte, otros capitanes como Oliver de Mauny, Arnaut Solier y Joffre Rechon obtuvieron el señorio de villas como Agreda, Villalpando y Aguilar de Campos, respectivamente (SuAREz FERNÁNDEZ, Luis, España cristiana. Crisis de la Reconquista. Luchas civiles, "Historia de España" dirigida por Ramón Menéndez Pidal, XIV, Madrid, 1976, p. 144).

39 CALDERÓN ORTEGa cita un documento de 5 de agosto de 1439, procedente del Archivo General de Simancas, en el que se recogen estas concesiones. ("La formación...", p. 425, nota 30; ver también, pp. 440 y 441 ). 
del millón seiscientos mil maravedies que había gastado en las gentes de armas que trajo al reino. Parece, por tanto, que el pago de los écorcheurs corrió en gran parte a cargo de Villandrando, lo cual demuestra la riqueza que había logrado amasar en Francia gracias al pago de los servicios prestados a Carlos VII y, no en menor medida, al saqueo, el pillaje y la extorsión. Sabemos que también Juan II contribuyó a cubrir los primeros desembolsos, como se desprende de la alusión que realiza el rey en sendas cartas al pago por unas lanzas ${ }^{40} \mathrm{y}$ al dinero que le ha enviado ${ }^{41}$, pero no debió resultar muy costoso para el monarca y el Condestable hacerse con el concurso del conde de Ribadeo, el cual, interesado en regresar a Castilla, corrió con la mayor parte de los gastos iniciales de la expedición, confiando en las mercedes prometidas por Juan $I 1$ y aceptando el aplazamiento del pago de sus servicios ${ }^{42}$.

La contratación de las compañías francesas en 1438 por parte del rey y el Condestable, respondía esencialmente a la necesidad de contar con un contingente de profesionales de la guerra que tuvieran experiencia, conocimientos y un singular armamento cuya eficacia era unánimemente reconocida. Estas fuerzas se caracterizaban por poseer sus propias armas y equipos así como una específica organización basada en unas unidades exclusivas - los arqueros y ballesteros montados - y emplear una táctica original. Para el contratante todo esto suponia contar con una superioridad táctica y bélica, así como un ahorro en material y la posibilidad de evitar ciertas carencias militares ${ }^{43}$. Todo ello, unido al retraso técnico y táctico existente en Castilla en cuestiones bélicas ${ }^{44}$, a pesar de ser una sociedad ancestralmente familiarizada con la guerra ${ }^{45}$, explica mejor el carácter decisivo que tenía la intevención de los mercenarios, lo que compensaba el

40 E en razón de las lanzas que m'embio suplicar, yo gelas embio libradas con vos. Carta de Juan II al Conde de Ribadeo, sin fecha pero muy probablemente del 6 de noviembre de 1438 (FABIE, ob. cit., apéndice XII, p. 223). Ver también: lbidem, pp. 439 y 440.

${ }^{41}$ En razón del dinero, días ha que vos mande embiar una parte dello ... E todavia vos entiendo más embiar, e proveer en todo por la manera que cumple a mi servicio e a honor vuestro. Carta de Juan II al conde de Ribadeo fechada en Medina el 30 de junio de 1439. (Ibidem, apéndice XIV, p. 225).

42 Aunque las mercedes otorgadas por Juan II fueron muy generosas, no puede compararse el coste que supuso para este monarca contratar los servicios de Villandrando con lo pagado y concedido por Pedro I y Enrique II, con ocasión de la guerra civil. (FowLER, "The wages...").

4.3 FOWLEF, ob. cit., p. 54.

${ }_{44}$ La nobleza castellana estaba acostumbrada a un tipo muy especial de guerra de frontera y en general despreciaba las tácticas procedentes de allende los Pirineos (RUSSELL, ob. cit., p. 104, CAstillo Cáceres, ob. cit., p. 133).

45 Las diferencias con las sociedades más cercanas se referian antes a la forma de combatir, a cuestiones tácticas, y al armamento antes que a la organización del ejército (LADERo QUESADA, "La organización..." p. 12). 
enorme coste de su contratación y los riesgos inherentes a la misma ${ }^{46}$. Un factor que contribuye decisivamente a hacer determinante la participación de los mercenarios en un conflicto era su especial organización; esta combinaba los tradicionales hombres de armas, es decir, la caballería más o menos pesada, con los ballesteros y, sobre todo a medida que avanza el siglo $x v$, con los arqueros montados, una fructífera unión que, según Fowler, otorgaba gran superioridad a estas fuerzas ${ }^{47}$. Fueron la insuficiencia y las limitaciones tácticas de la caballeria pesada, no muy abundante en Castilla por otra parte ${ }^{48}$, lo que dio lugar desde la segunda mitad del siglo XIV a la creación de una serie de unidades que, en busca de mayor efectividad, debian luchar de manera diferente, iniciando un proceso que culmina a fines del siglo $x v$ con la aparición de la infantería como arma independiente ${ }^{49}$. A idénticas razones responde el éxito alcanzado en los dos últimos siglos medievales en los campos de batalla por los arqueros montados. Fue en Francia donde a raiz de la derrota de Crecy se comenzó a combinar arqueros y ballesteros a caballo con los tradicionales hombres de armas, constituyendo un ejemplo más de la colaboración entre las distintas armas semejante al que ofrecía la caballería desmontada en relación con la infantería ${ }^{50}$. A lo largo del siglo $x v$ la proporción entre estas distintas fuerzas se invirtio, incrementándose progresivamente las nuevas unidades hasta superar a la caballería pesada en dos a uno, al tiempo que el arquero montado desplazaba al ballestero, lastrado siempre por lo engorroso de su arma ${ }^{51}$. La importancia de la intervención de tropas mercenarias en un conflicto y las consecuencias militares que se derivan de la misma, se pueden apreciar mejor si consideramos que los arqueros montados eran unas unidades prácticamente desconocidas en Castilla, lo que no impedía que fueran sumamente valoradas y reconocida su gran efectividad. Este aspecto se pone de manifiesto con ocasión de la venida de Rodrigo de Villandrando, pues el propio Juan II, cuando trata de lograr su intervención en el conflicto, alude de forma específica a la gente de armas $y$ arqueros que debía traer el routier, mostrando su estima hacia unas unidades muy superiores a las existentes en el reino cuyo empleo a veces era decisivo. La especial consideración que recibían en Castilla las tropas del conde de Ribadeo se revela incluso en la terminología. No se puede

$46 \quad$ Ibidem, p. 28.

47 FOWLER, ob. cit., p. 54.

48 LADERO QUESADA, “La organización...", p. 24, Vid infra, nota 76.

49 Ibidem, p. 26.

50 MOXo, ob. cit., pp. 87 y 88.

51 CONTAMINE, ob. cit., p. 126. 
dejar de señalar que tanto la Crónica de Juan $/{ }^{52}$ como la Crónica del Halconero ${ }^{53}$, al aludir a los mercenarios que acuden en ayuda de Juan II ${ }^{54}$, emplean el término combatiente ${ }^{55}$, el cual sin embargo no aparece en estas fuentes como sinónimo para referirse a las fuerzas realistas o nobiliarias, usualmente aludidas según sus caracteristicas: jinetes, rocines $u$ hombres de armas. Esta circunstancia parece revelar la voluntad de los cronistas de establecer una distinción entre las fuerzas de Villandrando y el resto de los participantes en el conflicto, de manera que podía pensarse que los mercenanos poseían algunos rasgos especiales que los diferenciaba de las fuerzas castellanas. Puede que fuera su carácter profesional, su procedencia extranjera ${ }^{56}$ o su especial organización en unidades originales y extrañas a Castilla, lo que establecía la especificidad de estas tropas en comparación con el Ejército real y las huestes nobiliarias y que, como tal, fue incluso captada por los cronistas de la época, llevando al uso de un término hasta entonces prácticamente desconocido ${ }^{57}$. Si la utilización de unas fuerzas diferentes a las existentes en el reino y cuyo concurso se presumía esencial, era una de las ventajas que aportaba la contratación de mercenarios, tampoco era desdeñable la fama y pericia del capitán que los dirigía, unas cualidades que debian de servir para amedrentar y disuadir a los adversarios. A este respecto poco cabe añadir acerca de la figura de Rodrigo de Villandrando, uno de los principales y más temidos jefes de compañía de la última fase de la Guerra de los Cien

52 Carta de Juan II al conde de Ribadeo fechada en Roa el 3 de marzo de 1439. (FABIE, ob. cit., apéndice XIII, p. 224).

5.3 PÉrez DE Guzman, Fernán, Crónica de Juan 11, “Crónica de los Reyes de Castilla", II, (ed. BAE), Madrid, 1953, cap. XXII (1439) p. 556.

54 Carpillo de Huete, Pedro, Crónica del Halconero de Juan II, (ed. de Juan de Mata Carriazo), Madrid, 1946, p. 292.

${ }_{55}$ El término combatiente para designar a una tropa o ejército rara vez se aplica, no sólo en el siglo XV sino incluso en el XIX (AlmiRANTE, José, Diccionario militar, Madrid, 1869). Tanto Juan CoRominas (Diccionario crítico etimológico de la lengua castellana, Madrid 1954) como Martín Alonso (Enciclopedia del idioma, Madrid, 1958) se remontan al siglo XVII y a la obra de Mariana como referencia de autoridad más antigua del vocablo. Por otra parte, ninguno de estos autores recoge la voz, ni siquiera el más especializado Martín ALonso en su Diccionario medieval español (Salamanca, 1986), aunque ambos incorporen en sus obras el término combatidor, pero como la forma primitiva derivada de batir con la que se designaba a cada uno de los soldados que componen un ejército, no a la totalidad de la fuerza. Por último, hay que señalar que hasta la fecha, las tareas de elaboración del Diccionario etimológico de la lengua española, emprendida por la Real Academia, no ha alcanzado la expresión que nos ocupa, privándonos de un mejor conocimiento histórico de la misma.

56 La Crónica del Halconero emplea, junto al término combatiente, el de franceses, para referirse a las tropas de Villandrando (ob. cit., pp. 291 y 294).

57 En el último tercio del siglo xv ya no se emplea el término combatiente para referirse a las tropas del conde de Ribadeo, quizás porque ya no se apreciaba la diferencia existente con el resto de las fuerzas. Fernando del Pulgar alude a ommes a caballo (ob. cit., p. 69). 
Años, cuya consideración en la época era semejante en muchos aspectos a la de Beltrán Du Guesclin ${ }^{58}$. A la hora de su contratación, el prestigio del conde de Ribadeo estaba acompañado de su lealtad a Juan II, un factor que tanto el rey como Álvaro de Luna valoraban enormemente, en especial en un contexto de deserciones generalizadas. Esta fidelidad respondía probablemente al agradecimiento de Villandrando al monarca, a su condición de reciente miembro de la nobleza, lo que le acercaba menos que otros señores a la Liga nobiliaria, y a las esperanzas de obtener nuevas mercedes.

Queda aludir, por último, a otro factor que posibilita la contratación de mercenarios extranjeros y que, en el caso que nos ocupa, contribuyó a facilitarla. Nos referimos a la existencia de tropas de estas características en condiciones de ser contratadas, es decir a la existencia de una oferta de mercenarios sin empleo al haber finalizado o encontrarse en una tregua el conflicto que hasta ese momento les proporcionaba trabajo ${ }^{59}$. Este hecho fue determinante en 1367, cuando dio lugar a un alquiler generalizado de compañías de routiers por parte tanto de Enrique de Trastámara como de Pedro I y el Príncipe Negro durante la guerra civil castellana ${ }^{60}$, y también lo será en 1439. En este año, como hemos señalado anteriormente, las bandas de écorcheurs dirigidas por Villandrando se encontraban vagando por el Rosellón desde hacía meses al no ser necesarios sus servicios tras haberse interrumpido las hostilidades en Francia, y sin tener la posibilidad de ser empleados de nuevo; al contrario, lo que cabía esperar era un enfrentamiento con las tropas de Carlos VII a causa de los desórdenes y el pillaje que ocasionaban los mercenarios. Ante este estado de cosas, dejar el reino era casi una exigencia para el conde de Ribadeo, de ahí su ofrecimiento a Juan II y la rápida aceptación de su contestación.

Hasta ahora hemos indicado las ventajas que aportaba la contratación de fuerzas mercenarias extranjeras, pero no se pueden esquivar los riesgos e inconvenientes que traía consigo recurrir a estas tropas. En primer lugar, hay que volver a hacer hincapié en el alto precio de sus servicios ${ }^{61}$, un elemento habitualmente señalado. Sin embargo, a pesar de haber sido importantes las mercedes y concedidas por Juan II a Villandrando, la contratación de este routier no fue ni mucho menos tan onerosa como la de

\footnotetext{
58 Véase Quicherat, (ob. cit.) y Fabie (ob. cit.).

ConTAMINE, ob. cit., p. 127.

Castillo cáceres, ob. cit.

Benito Rodriguez, "Las tropas...", p. 48.
} 
las compañías gasconas que llevó a cabo Pedro I en 1367. Otros peligros que traía consigo el alquiler de mercenarios era el del pillaje que podía producirse en el momento en el que, por cualquier razón, aparecía el descontento ${ }^{62}$, por no añadir la posibilidad de que estas fuerzas prolongasen su estancia en el reino más allá de lo conveniente y de la necesidad de sus servicios. A pesar de todo, la urgencia y la necesidad derivadas de la difícil situación en que se encontraban en 1439 Álvaro de Luna y Juan II, aconsejaban pasar por alto estos riesgos y proceder a su rápida contratación para intentar variar el curso de los acontecimientos.

A finales de 1438, cuando parecía que el Condestable todavía podía controlar la rebelión de los nobles y limitarla a las personas del Adelantado y el Almirante, Villadrando -quien, como hemos visto, había recibido instrucciones de permanecer expectante y en condiciones de acudir a Castilla si eran requeridos sus servicios por Juan II- se encontraba asolando el Rosellón y atacando las posesiones aragonesas en la región ${ }^{63}$. Estas acciones las llevaba a cabo aprovechando la presencia de Alfonso $\mathrm{V}$ en Italia con el objetivo de desatar la alarma en Aragón y Navarra ${ }^{64}$ y atentar contra los intereses de los Infantes, todo de acuerdo con las instrucciones de Álvaro de Luna que debió transmitir a Villandrando su sobrino Fernán Sánchez de Tovar, portador de las cartas de Juan II, o quizás el Arcediano de Cuenca, Juan Carrillo ${ }^{65}$. En esta situación se llega a febrero de 1439 , momento en el que se generaliza la rebelión señorial al producirse el llamamiento de los grandes alzados en Medina de Rioseco para unirse a la misma. La denuncia del gobierno del Condestable y la exigencia de su salida de la Corte eran unos objetivos ampliamente compartidos por la nobleza castellana, como lo demuestra el eco que tuvieron las cartas enviadas por el Almirante Enríquez y Pedro Manrique invitando a sumarse al movimiento ${ }^{0} 6$. Desde ese momento se generalizaron las deserciones de aquellos señores que se encontraban en las filas realistas, llegando al extremo de afectar a aquellos que tenían acostamiento con Álvaro de Luna ${ }^{67}$ e incluso a su propio suegro, el conde de Benavente. La pérdida de respaldo político y la falta del concurso militar de las huestes nobiliarias que

\footnotetext{
62 Vid supra. Nota 21

63 Fabie, ob. cit., p. 100. Quicherat, ob. cit., p. 164.

64 Los Anales de Zurita mencionan el intento de Villandrando de tomar Salses (cit. CALDERÓN, ob. cit., p. 423, nota 321 ).

65 FABIE, ob. cit., p. 108. QUICHERAT, ob. cit., p. 163.

66 SuÁrez Fernandez, Los Trastámara..., p. 153. Nobleza y..., p. 148. Porras Arboledas, ob. cit., pp. 205 y ss.

67 Porras arboledas, ob. cit., p. 205.
} 
se integraban en el Ejército real, era algo evidente a finales de febrero de 1439. Esta grave situación, uno de cuyos efectos inmediatos fue el traslado a Roa de la Corte, aceleró los preparativos de los realistas para fortalecer sus fuerzas ante un enfrentamiento que se adivinaba inminente. De acuerdo con estas críticas circunstancias se entiende la carta fechada en Roa el 3 de marzo, enviada por Juan II al conde de Ribadeo, a la sazón en la región de Toulouse, en la que destaca la urgencia de la llamada y la necesidad de su concurso. En ella le dice que deje todas las cosas y se ponga en camino lo antes posible e que por causa de arreos nin guarniciones nin de otra cosa que sea, non vos detengades. ${ }^{68}$ La misiva, en la que no se alude a pagos o recompensas que se sobreentienden acordadas, fue enviada por el arcediano de Cuenca, Juan Carrillo de Toledo, quien era portador de los permisos y cédulas reales que acreditaban que las fuerzas de Villandrando estaban al servicio del rey, a las que se debía franquear el paso y prestar ayuda ${ }^{69}$. Aunque Juan Carrillo debió contribuir a transmitir la premura con que se necesitaba ayuda y a procurar que los preparativos para iniciar la marcha se acortasen, la campaña no podía emprenderse inmediatamente. Preparar un ejército y una expedición en una época todavia invernal, en la que muchos de los soldados que habían participado en las correrías del otoño por el Rosellón habían sido licenciados ${ }^{70}$, no era una tarea sencilla. Prueba de ello son los casi cuatro meses que tardó el conde de Ribadeo en iniciar la marcha, un período demasiado largo si tenemos en cuenta que no tuvo problemas financieros, pues el mismo corrió desde un primer momento con los gastos de las tropas y no tenia que aguardar el envío de dinero. Quizás Villandrando quiso esperar a que la situación de Juan II y Álvaro de Luna se agravase aún más para hacer que su intervención resultase decisiva y fuera aún más valorada, consiguiendo de esta forma fortalecer su posición entre los partidarios del rey y obtener mayores recompesas. Aunque es posible que se encontrase con más dificultades de las previstas, la realidad es que la carta de Juan II no podía facilitar más las cosas. Tampoco puede pensarse en la existencia de algún problema o desacuerdo entre el rey y el routier que justificase el

6B FABIE, ob. cit., apéndice XIII, p. 224.

69 Quicherat, ob. cit., p. 172. Al contrario que el autor francés, FaBie (ob. cit., p. 106) no precisa quien llevó a Villandrando la carta de Juan II correspondiente al 3 de marzo. Anteriormente, Juan Carrillo había acompañado en noviembre de 1438 a Fernán Sánchez de Tovar a Toulouse y es muy probable que repitiese el viaje, como hombre de confianza que era el Condestable (Chacón, Gonzalo, Crónica de don Alvaro de Luna, ed. de Juan de Mata Carriazo, Madrid, 1940. p. 445), con el encargo de acelerar la partida del conde de Ribadeo y como portador de documentos, instrucciones y quizás dinero, que facilitase la llegada de estas tropas a Castilla.

70 QUICHERAT, ob. cit., p. 173. 
retraso en la partida, pues incluso el monarca había accedido a la petición de honores realizada por don Rodrigo para sus capitanes. La realidad era que mientras en Castilla se esperaba la llegada de los mercenarios franceses, cuyos servicios se habían procurado con la mayor discreción, la situación del partido realista empeoraba cada vez más. La rebelión nobiliaria rompia el marco geográfico de Medina de Rioseco y a mediados de marzo los nobles tomaban Valladolid, convertida en su base de operaciones, al tiempo que redoblaban sus llamamientos. Los efectos no se hicieron esperar. Juan II y el Condestable se retiraron de Roa a la más segura ciudad de Cuéllar con el grueso de sus fuerzas, al tiempo que adoptaban un dispositivo defensivo basado en una serie de villas de la zona del Duero en las que desplegaron algunas fuerzas ${ }^{7 \dagger}$. Paralelamente se inició una concentración de fuerzas nobiliarias en Valladolid, las cuales se vieron continuamente incrementadas mediante la incorporación de numerosos nobles con sus huestes en un incesante goteo a lo largo de varios meses ${ }^{72}$. En estos momentos ya había dos ejércitos en presencia y podía aventurarse la posibilidad de un choque entre ambas facciones.

Las fuerzas enfrentadas, a pesar de contar con diferencias, eran muy similares en su estructura y características. Los ejércitos señoriales reproducian en su organización el Ejército real ${ }^{73}$ y se formaban gracias a las rentas de los nobles y a su condición de señores jurisdiccionales ${ }^{74}$. El aparato militar que podían levantar los magnates, la disponibilidad que tenían de medios y hombres, tanto caballeros como vasallos, y la propia vocación guerrera de la nobleza, hacían que estos contingentes fueran unas excelentes fuerzas de combate ${ }^{75}$.

Sin embargo, la diversidad de su formación le daban un carácter heterogéneo ${ }^{76}$, una cualidad que unida a la diversidad de armamento, equipo

71 Crónica de Juan II, p. 551. Halconero, p. 279.

72 L.as aportaciones de las huestes nobiliarias que se suman a las existentes en Valladolid se pueden seguir en las crónicas de la época. Conviene recordar que las mesnadas señoriales era frecuente que tuvieran entre 150 y 400 hombres de armas y jinetes, lo que da idea de la magnitud de las fuerzas concentradas (LADERO QUESADA, La organización..., p. 22).

73. BECEIRO PITA, Isabel, "Los estados señoriales como estructura de poder de la Castilla del siglo Xv", en Realidad e imágenes del poder. España a fines de la Edad Media, coord. de Adeline Rucquoi, Salamanca, 1938, p. 29.

74 LADERO QUESADA "La organización...", p. 22 GRASSOTTI, ob. cit., pp. 162 y ss.

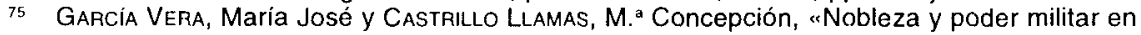
Castilla", Medievalismo, n. ${ }^{\circ} 3,1993$, p. 30. Montero Tejada, Rosa M. ${ }^{a}$. Nobleza y sociedad en Castilla. El linaje Manrique (siglos XIV-Xvi), Madrid, 1996, pp. 239-267.

${ }_{76}$ Las huestes señoriales estaban formadas por la guardia personal del señor, los jinetes $u$ hombres de armas, de vasallos con acostamiento, asi como peones procedentes de villas y lugares de señorio, aunque estas tropas tenían menor importancia. (BECEIRO PITA, ob. cit., p. 299. LADERO QUESADA, "La organización...", p. 22). 
y mando, constituían una serie de deficiencias que lastraban a estas tropas y limitaban su eficacia ${ }^{77}$. Por otra parte, hay que señalar que la hueste de cada noble era, por la inversión realizada en su creación y mantenimiento y por lo restringido de este recurso, una parte importante de un patrimonio que había, a un mismo tiempo, de conservar pero también de utilizar de forma rentable para sus intereses. Estos objetivos contradictorios que caracterizan a los ejércitos privados por su condición económica de bien patrimonial, compatible con la de instrumento político, también los comparten las fuerzas realistas, pues este tipo de tropas al ser el monarca en bastantes aspectos un noble más, poseían muchos rasgos en común con las huestes nobiliarias ${ }^{78}$. Así, en 1439 , aunque las fuerzas en presencia tenían características propias, eran más numerosos los elementos que compartían que aquellos que los diferenciaba, lo que permite añadir a las deficiencias señaladas al ejército nobiliario, en su mayor parte extensibles a las tropas reales, otras carencias comunes a los ejércitos medievales del Cuatrocientos. En primer lugar, hay que apuntar la escasa capacidad operativa de estas fuerzas, fruto de sus limitaciones militares y temporales, y la diversidad de sus elementos, lo que suponía fijar la duración de su servicio a un período de tiempo previamente estipulado y obligaba a llevar a cabo campañas cortas, al tiempo que a afrontar problemas de disciplina. La pretensión de reducir en el tiempo las operaciones tanto por las razones señaladas como por su elevado costo, chocaba con la escasa capacidad ofensiva que poseían los ejércitos. Esta cuestión impedía resolver la guerra con una batalla campal decisiva y provocaba el alargamiento de las operaciones en las que la escaramuza, la cabalgada y el asalto por sorpresa eran las formas habituales de guerrear, estando todas ellas definidas por el escaso número de combatientes y lo limitado de sus efectivos ${ }^{79}$. Ante este tipo de combate no es de extrañar que en Castilla fuera más abundante la caballería ligera, a la jineta, de origen musulmán y muy adecuada para la algarada, que la caballería pesada, los hombres de armas que constituían la unidad característica de la

7 Garcia Vera-Castaillo llamas, ob. cit., p. 30.

78 El Ejército real tenia una composición aún más diversa que las fuerzas señoriales pues sumaba al tipo de contingentes que se integraban en estos, las milicias concejiles, es decir, las tropas de caballeria e intantería que proporcionaban las ciudades, los guardas reales, las huestes de las Órdenes Militares y los vasallos del rey que tenian acostamiento con el monarca. No obstante esta diversidad, la parte esencial del Ejército castellano la constituian las tropas nobiliarias que acudían a la llamada del rey. (Vid. supra, nota 31).

79 Ladero Quesada, Miguel Ángel, Milicia y economía en la Guerra de Granda. El cerco de Baza, Valladolid, 1965, pp. 37-38. Castilla y la conquista..., p. 15. Redondo Diaz, ob. cit., p. 63. CONTAMINE, ob. cit., p. 274. 
nobleza ${ }^{80}$. Otros factores que lastraban la operatividad y eficacia de los ejércitos eran sus reducidos efectivos ${ }^{81}$ y la enorme importancia que tenían los contingentes aportados por la nobleza, una cuestión que se revela de forma dramática en aquellos momentos en los que los señores desoían mayoritariamente la llamada real por razones políticas, como ocurrió en 1439 en Castilla cuando gran parte de la nobleza se sumó a la rebelión contra Álvaro de Luna. En esta ocasión, la privación de las huestes señoriales, incluidos los contingentes eclesiásticos y de las Órdenes Militares, dejaba prácticamente en cuadro al Ejército real ya que estas fuerzas, a pesar de sus limitaciones, eran las mejor armadas, la más experimentadas $y$, si se nos permite, incluso las más profesionales junto a los guardias reales. Su falta dejaba al monarca en una difícil situación, lo que explica el recurso a medidas extraordinarias como era la concesión de mercedes desmedidas a los señores indecisos y a buscar el apoyo en el exterior, siendo la contratación de mercenarios una de las posibilidades existentes.

Los diferentes episodios a lo largo de los cuales se desarrolló la guerra civil castellana en la primera mitad del siglo xv, tuvieron un escaso contenido militar, estando definido el conflicto por las negociaciones, las conversaciones y las treguas, una circunstancia que se ve favorecida por las reglas de la caballería, tan proclives a los ritos y los desafíos ${ }^{82}$. Las razones

${ }^{80}$ El modelo castellano de hombre de armas difiere de la lanza francesa o borgoñona ya que al contrario que esta unidad, acude al combate acompañado tan sólo de algún paje y nunca lleva los cinco servidores que acompañan al caballero francés. Las diferencias con el jinete vienen dadas por el tipo de armamento y la protección empleada, más sólida en el hombre de armas que en el caballero a la jineta, quién lieva menos partes metálicas y mayor cantidad de defensas de cuero. (LAdero QueSADA, Castilla y la conquista..., pp. 13 y 14). Sobre este tipo de unidades se puede ver también, en relación con la Península Ibérica, REDONDO Diaz, ob. cit., pp. 81 y ss. QuicherAT, ob. cit., pp. 9-11. SOLER DEL CAMPo, Álvaro, ob. cit., y La evolución del armamento medieval en el reino castellano-leonés y Al-Andalus (siglos XII-XIV). Madrid 1993. Tradicionalmente se ha aludido a la escasa importancia de la caballería en Castilla, siendo achacada por algunos autores a la carencia de caballos en el reino (HALE, J.R., Guerra y Sociedad en la Europa del Renacimiento, 1450-1620, Madrid, 1990, p. 63) donde eran más habituales las mulas; otros autores prefieren relacionar esta circunstancia con las escasas batallas campales que se dieron en el reino y con la limitada eficacia de este arma en el tipo de operaciones militares más frecuentes (LADERO QUESADA, "La organización...", p. 24).

B. HALE, ob. cit., pp. 72 y ss. REDONDO DiAZ, ob. cit., pp. 63-65.

82 Hay numerosos ejemplos en las crónicas del siglo xv de cómo las normas de caballería regulan la guerra, aunque podemos escoger como muestra lo sucedido en marzo de 1441, cuando las fuerzas nobiliarias y de los Infantes de Aragón se intercambian farautes con el Condestable anunciando las diferentes maniobras que van a iniciar (Crónica Juan I/ p. 576). Véase al respecto KEEN, M. La caballeria, Barcelona 1986. DuBY, Georges, Las tres órdenes o lo imaginario del feudalismo. Barcelona, 1983, HuIzINGA, J. El otoño de la Edad Media, Madrid, 1978, Stefano, Luciano de, La sociedad estamental de la Baja Edad Media española a la luz de la literatura de la época, Caracas, 1966. TORRES FONTES, Juan, "Don Fernando de Antequera y la romántica cabalieresca", Miscelánea Medieval Murciana, V, 1980, pp. 83-120. SÁnchez PRIETo, Ana Belen, Guerra y gue- 
que dan lugar a esta forma de conflicto son de tipo político entre otras causas, pues lo poco definido de cada uno de los bandos, en los que los cambios de filas según evolucionaba la coyuntura era algo habitual, impulsaba al pacto y al convenio. Pero también había motivos de carácter militar como el tradicional rechazo existente durante la Edad Media a la batalla, al enfrentamiento directo y decisivo que muy raras veces se produce y, cuando se da, es en realidad una escaramuza de mayores dimensiones que las habituales ${ }^{83}$. Había así mismo una limitación previa a todo conflicto que era propia de la época, pues para la mayoría de los contendientes resultaba muy arriesgado jugarse el resultado del mismo a un sćlo golpe, llegar al choque frontal y afrontar las pérdidas que supone ${ }^{84}$. Esta circunstancia se pone de manifiesto en Castilla durante el periodo que nos ocupa al contemplar las continuas maniobras llevadas a cabo por Álvaro de Luna, con la intención de provocar un choque frontal que implicase a la mayor cantidad de fuerzas posibles y poder resolver de un golpe el enfrentamiento con los infantes de Aragón y la oligarquía nobiliaria. El Condestable tuvo que esperar más de veinte años para llegar a la batalla de Olmedo, cuando ya su posición política se había erosionado irremediablemente y su triunfo era insuficiente. Lo ocurrido desde un punto de vista militar durante las diferentes fases que atraviesa la guerra civil castellana entre 1420 y 1450 , revela una concepción del ejército definida esencialmente por ser un elemento de negociación y presión política, una característica por otra parte esencial a la institución, antes que por ser un instrumento que permitiese obtener y explotar un triunfo militar. El atribuir al ejército una función casi exclusivamente política en detrimento de las militares, permite referirse al conflicto castellano de la primera mitad del Cuatrocientos como una guerra limitada, de baja intensidad, debido a lo restringido, desde un punto de vista bélico, de sus objetivos y medios. En este contexto, el resultar derrotado o salir del enfrentamiento con las fuerzas seriamente mermadas significaba, especialmente para los nobles, verse privado de un instrumento esencial de acción política, así que para los grandes sus huestes eran antes elementos de presión y disuasión, fuentes de poder y de incremento de riqueza y patrimonio, que instrumentos bélicos. A esta concepción

rreros en España según las fuentes canónicas de la Edad Media, Madrid, 1990. Grassotti, Hilda, "El deber y el derecho de hacer guerra y paz en León y Castilla, Cuadernos de Historia de España, LIX-LX, 1976, pp. 221-296. RIQuER, ob. cit., y Vida caballeresca en la España del siglo XV, Madrid, 1965. Mitre, Emilio, La guerra de los Cien Años, Madrid, 1990, p. 79. Rodriguez Velasco, Jesús D., El debate sobre la caballeria en el siglo xv. La tratadistica caballeresca castellana en su marco europeo, Salamanca, 1996. OREJudo, Antonio (editor), Cartas de batalla, Barcelona, 1993.

3 CONTAMINE, ob. cit., pp. 274 y 286.

84 MitRE, ob. cit, p. 80. KEEN, ob. cit., pp. 290-294. 
contribuye el que durante la Edad Media el triunfo militar y el exterminio del adversario fueran unos objetivos que ni se contemplaban ni, por el escaso desarrollo de los medios de destrucción, pudieran alcanzarse, por lo que era usual valorar antes que las ventajas y consecuencias de la victoria, las pérdidas, sus repercusiones y la capacidad de asunción de las mismas. Este ejercicio, especialmente intenso entre quienes tenían unos recursos limitados en rentas y hombres, se imponía como un requisito esencial de toda campaña. No es de extrañar, por tanto, que el conflicto civil castellano fuera una sucesión de encuentros cuando no fallidos, de escasa entidad, una serie de treguas y pactos donde la fuerza se preservaba sin arriesgarse. Este modo de empleo de los medios militares fue especialmente característico de la oposición nobiliaria y contrastaba con la actitud del partido realista pues, aunque Juan II y Álvaro de Luna también participaban de una cierta inclinación hacia los acuerdos, intentaban provocar el choque directo para resolver el conflicto. Probablemente, la contratación o llamada a Rodrigo de Villandrando por parte de Juan II a iniciativa del Condestable, respondia entre otras razones a la pretensión de imponerse definitivamente a sus rivales aprovechando la situación de enfrentamiento declarado.

La consideración y extensión de la rebelión nobiliaria y la concentración de huestes señoriales en Valladolid a lo largo del mes de marzo de 1439 , llevaron a don Álvaro a tomar una decisión trascendental que pone de manifiesto lo dificil de su situación y su aislamiento político. El Condestable decidió acudir en busca de ayuda a los Infantes de Aragón, quienes se encontraban fuera de Castilla desde principio de la década. Al recurrir a sus tradicionales enemigos, Álvaro de Luna no valoraba tanto el peligro que representaba la vuelta de los hijos de Fernando de Antequera a la vida política castellana, como su confianza en que restablecerian la situación en favor de Juan II. Se basaba en que, a pesar de las diferencias que le separaban, al ser ellos mismos de linaje real no verían con buenos ojos la consolidación del poder de los grandes. No era muy disparatado suponer que a los infantes no les interesaba que se institucionalizase en Castilla la influencia de los principales linajes sobre la monarquía, pero el error dei Condestable aparece al valorar los criterios y prioridades de los aragoneses, quienes anteponían ante todo sus intereses patrimoniales en el reino. En consecuencia, Juan y Enrique no desoyeron la invitación de Álvaro de Luna y rápidamente se dirigieron al reino castellano con el objetivo esencial de recuperar sus posesiones perdidas en 1430 y consolidar su poder e influencia, para lo cual cada uno de ellos se alineó en un bando distinto según sus preferencias, quedando de esta forma asegurados sus intereses. $\mathrm{El}$ infante don Enrique, tras un corto periodo durante el cual su postura parecía equívoca, se unió a la Liga nobiliaria, mientras que Juan 
de Navarra, quien al poco de llegar se arrogó y obtuvo el papel de mediador, se sumó al bando de su primo Juan II. A lo largo de los meses de abril y marzo se desarrollan a impulso del rey de Navarra continuas negociaciones entre dos bandos, al tiempo que la rebelión se extendía por Andalucía y el Maestrazgo de Santiago y continuaba el incremento de las fuerzas de los grandes mediante la llegada a Valladolid de nuevos partidarios. La ambigüa actitud de Juan de Navarra y la defección del infante don Enrique obligaron a Álvaro de Luna a renunciar a imponerse a la oposición nobiliaria y al abandono momentáneo del recurso a las armas. Sin embargo, las conversaciones no impedían los continuos despliegues y maniobras por parte de ambos bandos para controlar diversas plazas ${ }^{85}$. Valladolid, el núcleo de la rebelión, era un activo centro desde donde la Liga nobiliaria enviaba expediciones para controlar el área del Duero y reducir el margen de maniobra de los realistas. Un buen ejemplo de esta táctica lo tenemos en la salida de Valladolid de Pedro de Quiñones, al frente de mil hombres de armas y cincuenta jinetes, con el objetivo de impedir que Gonzalo de Guzmán llegase con tropas del Ejército real a Mucientes, guarnecida por 150 jinetes, con objeto de reforzar la villa ${ }^{86}$.

El desarrollo de las conversaciones celebradas en Tordesillas revelaba lo complicado de las mismas y el adverso cariz que iban tomando para los intereses de Álvaro de Luna y Juan II, quien al participar en ellas se vio rebajado al nivel de un contendiente político más. Estas razones, junto a la nunca abandonada intención del Condestable de recurrir a la fuerza para acabar con sus enemigos, así como la probable noticia de la pronta llegada de Villandrando con unas tropas que, por su calidad y cantidad, podían desequilibrar la situación, y el apoyo del tercer estado urgentemente convocado a Medina, dando respaldo a Juan If en su rechazo a compensar a los nobles con villas de realengo ${ }^{87}$, dieron al traste con las negociaciones $y$ llevaron al recurso de las armas. La confianza del Condestable en vencer a la Liga gracias al concurso de las fuerzas del conde de Ribadeo, la aparente neutralidad de Juan de Navarra y la presión en favor de la lucha realizada por Gutierre de Toledo, temeroso de perder, como Villandrando, las donaciones recibidas en 1430, también pesaron sin duda en la decisión de los realistas de abandonar Tordesillas ${ }^{88}$. Durante los meses que duró la tre-

85 Crónica de Juan II, cap. V-XI (1439). Crónica del Halconero, cap. 236-239.

86 Las cifras de los efectivos, como suele ser habitual en las crónicas, difieren entre sí pues Carrillo de Huete alude a 150 rocines y Pérez de Guzmán sólo se refiere a 100 (Crónica de) Haiconero, p. 279, Crónica de Juan 11 , p. 351).

87 SUÁREZ FERNÁNDEZ, Los Trastámara..., p. 157.

88 SuÁrez Fernández, Nobleza..., p. 150. 
gua se celebraron numerosos encuentros y se desarrolló una denodada actividad política, pero también ambos bandos aprovecharon la situación para fortalecer su respectiva capacidad militar ${ }^{89}$. Las fuerzas en presencia en el momento en que se produce la ruptura de negociaciones eran muy semejantes. De acuerdo con las cifras que dan las crónicas, la Liga nobiliaria contaría entre los dos mil quinientos y tres mil hombres de armas, siendo difícil precisar cuál era la cantidad de jinetes; estas fuerzas eran el fruto de la suma de las distiritas huestes nobiliarias que habían ido acudiendo a Valladolid, a las que había que añadir un número indefinido de peones, lanceros $y$ ballesteros que se incorporaron a última hora, procedentes probablemente de los cercanos señorios de los Enríquez ${ }^{90}$. El Ejército real oscilaria según las mismas fuentes entre los tres mil y cinco mil hombres de armas, teniendo en cuenta que en esta última cifra estarian incluidas las fuerzas de Juan de Navarra, quien todavia aparecia entre los partidarios de Juan II. Hay una coincidencia de las crónicas en fijar en tres mil hombres de armas el contingente que se concentra en Olmedo a principios de abril de 1439. Este Ejército real estaría compuesto por los guardas reales, el pequeño contingente de fuerzas permanentes que intentó crear el Condestable desde su !legada al poder, el cual desataba el recelo de los grandes y las quejas de las ciudades por su carestia ${ }^{91}$; a estos guardas hay que sumar los señores con los que el monarca tuviera establecido acostamiento y aquellos otros que hubieran acudido a su llamada, de acuerdo con su condición de vasallos. Se pueden señalar las huestes del Arzobispo de Toledo, Juan de Cerezuela, hermanastro de Álvaro de Luna, del conde de Haro así como las fuerzas que, como un noble más, pudiera aportar el Condestable, a los que se uniría la caballería concejil. Eran tres mil hombres de a caballo entre jinetes y lanzas, a los que habría que añadir un numero indeterminado de peones, los cuales ni siquiera son mencionados por las crónicas. En esta situación de práctica igualdad, la aportación del conde de Ribadeo y sus combatientes, con la superioridad que les otorgaba estar organizados a la francesa ${ }^{92}$, es decir, combinar arqueros montados con hombres de armas, tenía una importancia decisiva.

89 Todavía a finales de mayo de 1439 se produce la incorporación a las filas de los rebeldes de Fernán Pérez de Andrade, quien llega a Valladolid con una hueste integrada por 200 hombres de armas (Crónica de Juan II, p. 554).

90 Tanto la Crónica del Halconero (p. 289) como la Crónica de Juan I/ p. 555), dan unas cifras tan exageradas como la de veinte mil peones.

91 En 1421 Álvaro de Luna decidió que se quedasen junto al rey para su guardia mil lanzas, lo que provocó que en las Cortes de Toro en 1426, los procuradores solicitaran al monarca que se suprimieran o, al menos, que se redujeran (Crónica de Juan II, pp. 411 y 426).

${ }_{92}$ QUICHERAT, ob. cit., p. 175. 
El 9 de junio de 1439, Rodrigo de Villandrando todavía continuaba en suelo francés ${ }^{93}$, aunque poco después se puso en marcha con sus fuerzas, transcurridos más de tres meses desde que se produjo la urgente solicitud de ayuda de Juan II, para encontrase con el monarca y el Condestable. Esta vez parecia que la ruptura de negociaciones iba a conducir inevitablemente al enfrentamiento entre los realistas y los grandes. El Almirante y el Adelantado debieron conocer la salida de Villandrando de Francia casi al mismo tiempo que se producía su llegada el 23 de junio a Villafranca de Montes de Oca, villa situada entre Burgos y Santo Domingo de la Calzada. El camino natural que debería haber seguido la expedición del conde de Ribadeo desde sus bases francesas, era muy semejante al seguido por el Príncipe Negro y Pedro I en $1367^{94}$ : entrar en la Península atravesando Roncesvalles, continuando por Pamplona y Logroño hacia Burgos; no obstante, aunque nada hay acerca del itinerario seguido por Villandrando, es difícil pensar que estas tropas pudieran cruzar sin problemas los dominios de Juan de Navarra. Se puede aventurar que hubieran forzado el paso, pero el riesgo corrido al cruzar los Pirineos ${ }^{95}$ con la hostilidad navarra y atravesar todo el reino, permite deshechar esta posibilidad que, sin duda, hubiera sido recogida por textos de la época. Cabe suponer también que, en caso de haber intentado el routier penetrar en Navarra, el infante y rey don Juan habría abandonado inmediatamente su neutralidad alineándose acto seguido con la Liga nobiliaria. A pesar de todo, la presencia del conde de Ribadeo en Villafranca de Montes de Oca hace difícil imaginar un itinerario diferente al más cómodo y rápido seguido en 1367 por el Príncipe Negro y sus compañías anglogasconas, al menos hasta Logroño, aún a sabiendas de que no pudo emplearlo. La alternativa a este camino sólo puede incluir, tras entrar en la Península Ibérica por territorio castellano, a Vitoria, desde donde era más prudente y rápido marchar a Burgos, vía Miranda de Ebro, que dirigirse a Santo Domingo. Sea como fuere, y cabe pensar como hipótesis más probable que de la capital alavesa se encaminase a Logroño o a Santo Domingo antes que atravesar el reino navarro, las primeras noticias que llegaron a la zona del Duero acerca del conde Ribadeo le sitúan ya en la citada villa de Villafranca de Montes de Oca. Sus fuerzas estaban formadas por tres

93 Ibidem, p. 174.

94 Castillo Caceres, ob. cit.

95 La importancia que tenía para la expedición anglogascona en 1367 contar con la seguridad de atravesar Roncesvalles sin problemas, se pone de manifiesto en las negociaciones mantenidas con Carlos II de Navarra y en el papel que desempeña este monarca en el curso de los acontecimientos. Ibidem, p. 116. 
mil hombres, una cifra en la que todas las fuentes coinciden, todos ellos montados y acostumbrados a marchar pues en trece dias Rodrigo de Villandrando y sus écorcheurs pasan de la zona de Toulouse a las cercanías de Burgos.

La sola noticia de la presencia de los mercenarios en Castilla tiene repercusiones inmediatas desde un punto de vista militar, ya que provoca una serie de maniobras de las fuerzas nobiliarias encaminadas a evitar que las compañías francesas se uniesen a las fuerzas de Juan II. La reacción de Fadrique Enríquez y Pedro Manrique fue rápida, contrastando con la parsimonia que acompañaba a otras iniciativas semejantes, lo que nos da idea de la importancia que concedían a las fuerzas de Villandrando y la confusión que debía existir acerca de su exacta localización en los primeros momentos. El mismo 23 de junio salió de Valladolid en dirección a Roa un primer contingente al mando de Pedro de Estúñiga, conde de Ledesma, acompañado del adelantado de Galicia, Diego Sarmiento, formado por mil quinientos jinetes ${ }^{96}$, caballería ligera muy apropiada para la acción emprendida en la que la rapidez era algo esencial. Poco después, el 25 de junio, salía de la capital vallisoletana el propio Almirante Enríquez en dirección a Renedo al frente de mil trescientos hombres de armas con la intención de apoyar a las fuerzas al conde de Ledesma. Debió existir un cierto retraso en la llegada de noticias a Valladolid, pues probablemente Villandrando ya había rebasado Burgos cuando Pedro de Estúñiga se puso en marcha. A pesar de lo decidido y rápido de la respuesta de los nobles rebeldes, los movimientos emprendidos no lo fueron tanto, ya que el conde de Ledesma tardó casi cuatro días en recorrer la distancia existente entre Valladolid y Roa, un tiempo que parece excesivo si tenemos en cuenta que era un ejército compuesto esencialmente por jinetes. Es evidente que la llegada de Villandrando y sus tropas dio lugar a las primeras iniciativas de carácter netamente militar que se efectuaron en el contexto de la guerra civil. Mientras tanto, el conde de Ribadeo acompañado de Juan Carrillo, arcediano de Cuenca y enviado de Juan II, había llegado con sus tropas a Roa sin ningún impedimento ${ }^{97}$. Sin embargo, la situación

96 En las crónicas se usa de forma indistinta rocín y jinete para designar a la caballeria ligera o a la jineta. Entre los muchos ejemplos que se pueden citar, tenemos la Crónica de Juan II cuando alude a cien jinetes enviados a Tudela de Duero a los que luego se refiere como rocines, (pp. 551 y 553).

97 Quicherat (ob. cit., p. 177 nota 3) alude a un manuscrito, ya desaparecido, escrito en el siglo xvil por un segundo bisnieto de Rodrigo de Villandrando, dedicado exclusivamente a la campaña castellana de este caballero, del que incluso da su título: El socorro del conde de Ribadeo, Rodrigo de Villandrando, al rey don Juan II, con todos los privilegios, cédulas y cartas reales pertenecientes a aquella acción, de Rodrigo Gómez de Sarmiento. 
parecia complicarse pues la villa, probablemente alarmada ante la presencia de unas fuerzas numerosas y quizás conocedora de la fama de su capitán, cerró sus puertas a los franceses y les negó la entrada. En ese momento Villandrando estaba frente a una ciudad que le era hostil, tras una marcha realizada con rapidez y a punto de avistar a las primeras fuerzas de la Liga, un panorama difícil que se resolvió gracias a las cartas y poderes reales que portaba el arcediano de Cuenca a nombre del conde de Ribadeo, las cuales consiguieron vencer las reticencias de la villa y permitir la entrada de los mercenarios. Podía suponerse que estos combatientes, acostumbrados al pillaje sistemático como forma de vida, habrían llevado a cabo algún saqueo o causarian desórdenes en la ciudad burgalesa, pero nada registran las crónicas al respecto, por lo que cabe imaginar que la disciplina impuesta por Villandrando entre sus soldados y capitanes era muy estricta. Al poco de instalarse los mercenarios en Roa, llegó el conde de Ledesma a las cercanias de la villa. Lo sucedido después tiene un desarrollo contradictorio, pues las crónicas divergen en los datos e información. Según el relato de la Crónica de Juan $/{ }^{98}$, Pedro de Estúniga recibió la noticia de la llegada de Villandrando a Roa cuando estaba con sus fuerzas a una legua de la ciudad. Inmediatamente decidió enviar a 300 jinetes para entablar combate y provocar la salida de las compañías. De acuerdo con esta versión, el combate entre ambos contingentes se produjo el mismo 27 de junio. Por el contrario, Carrillo de Huete nos refiere cómo el conde de Ledesma llegó ante Roa el mismo día 27, una vez establecidas en la ciudad las fuerzas mercenarias, procediendo a acampar a una legua y enviando a continuación a 300 jinetes para escaramucear con los franceses ${ }^{99}$. Fuera antes de acampar o bien fuera desde su campamento desde donde salieron los jinetes enviados por el conde de Ledesma, la realidad es que este noble no sólo no rehuyó el combate, sino que incluso buscó el enfrentamiento mostrando arrojo y decisión, pasando por alto la superioridad y el prestigio de las tropas que tenía enfrente, del que sin duda era conocedor. Quizás emprendiese su acción confiando en que el Almirante Enríquez pudiera acudir en su ayuda con sus fuerzas $o$, al menos, enviar parte de las mismas, pero es una posibilidad que hay que rechazar pues los dos días que llevaba de ventaja el conde de Ledesma hacen esta maniobra muy difícil y sumamente arriesgada. El hecho de encontrarse las tropas nobiliarias más frescas que las del conde de Ribadeo, sin duda cansadas tras su traslado un tanto

98 Crónica de Juan II, p. 556.

99 Crónica del Halconero, p. 293. 
apresurado desde el sur de Francia, puede contribuir a explicar el por qué de la decisión de entrar en combate adoptada por Pedro de Estúñiga y la razón por la que Villandrando no aprovechó la oportunidad de acabar con estas fuerzas, muy inferiores en número, una iniciativa para la cual quizás no contaba con la autorización real. El conde de Ribadeo, al ver desde Roa las fuerzas enviadas por el conde de Ledesma, ordenó que saliera a su encuentro un contingente de 200 arqueros montados y 200 hombres a caballo ${ }^{100}$ al mando de uno de sus principales capitanes, Juan de Salazar, experimentado soldado, afamado routier $y$ hombre de confianza de Rodrigo de Villandrando ${ }^{101}$. El choque entre ambas fuerzas tuvo lugar en las afueras de Roa y debió adquirir cierta magnitud pues en ambos bandos hubo heridos y muertos, algo que destaca en el contexto militar del siglo XV y muy especialmente en el reino castellano donde, como hemos señalado, los enfrentamientos fueron escasos y de reducidas repercusiones. Hay que señalar que esta pequeña batalla de Roa no implicó al grueso de las fuerzas de los contendientes, ya que tanto el conde de Ledesma como el de Ribadeo permanecieron al margen de la misma. Según Quicherat ${ }^{102}$, Juan de Salazar, para salir airoso del choque, se limitó a aprovechar la ventaja que le otorgaban sus unidades de arqueros y ballesteros montados, un tipo de tropa que como hemos visto era característica de las compañías de mercenarios y cuya efectividad era proverbial. En un principio mantuvo a los jinetes del conde de Ledesma a distancia utilizando los arqueros para pasar después a arrollarlos empleando sus hombres de armas ${ }^{103}$. Tras finalizar el combate al anochecer, el conde de Ledesma se replegó hacia el suroeste de Roa y acampó en San Martín de Rubiales, a cierta distancia de la ciudad burgalesa, con la intención de esperar acontecimientos. Desde este lugar Pedro de Estúñiga intentaba evitar que se produjera el enlace entre las fuerzas del conde de Ribadeo y las de Juan II, mientras aguardaba la llegada de las tropas del Almirante Enríquez, las

100 Crónica de Juan II, p. 5. El Halconero señala a 200 ballesteros y 200 arqueros.

101 Juan de Salazar era probablemente el hombre de confianza del conde de Ribadeo, a quien acompañó en varias campañas como la del Rosellón en 1438, durante la cual se hizo cargo de parte de las tropas de su ausencia. (QuICHERAT, ob. cit.,p. 166). Sin embargo, su cercanía al routier se manifiesta de forma especial cuando en septiembre de 1439, siguiendo las instrucciones de Villandrando en cumplimiento de los acuerdos de Castronuño, encabeza las compañias que habían venido a Castilla en su retirada hacia el sur de Francia. Aunque Salazar no consiguió la celebridad de su capitán, sí adquirió cierto renombre como modelo de caballero mercenario, mitad soldado mitad bandido, capaz de saquear y asesinar al tiempo que admirar a los héroes de los relatos caballerescos hasta el extremo de poner a sus hijos nombres como Tristán, Lanzarote, Héctor y Galeas (HALE, ob. cit., p. 45).

t02 QUICHERAT, ob. cit., p. 175.

103 Ibidem. 
cuales ya habían partido de Renedo en dirección al campo de batalla. En el momento en que el rey y Álvaro de Luna tuvieron noticia de la llegada de Villandrando a Roa con sus fuerzas, enviaron inmediatamente al conde Castro al frente de 1.300 hombres de armas con objeto de reforzarle. Según el infante don Enrique, esta iniciativa fue la que dio lugar a la salida de Fadrique Enríquez en apoyo del conde de Ledesma ${ }^{104}$. El almirante llegó a las cercanias de Roa el 30 de junio e instaló sus reales en Encinas de Esgueva, al noroeste de la ciudad burgalesa. Con esta maniobra los nobles intentaban evitar que Villandrando pudiera dirigirse con sus fuerzas al escenario principal de los acontecimientos, el área de ValladolidMedina-Cuéllar, donde se encontraba Juan II y la Corte. Así, mientras Pedro de Estúñiga cerraba el paso hacia Valladolid por Peñafiel, Fadrique Enríquez hacía lo propio por el norte. La situación parecía que de nuevo iba a desembocar en la tregua y en las inevitables conversaciones. En el mismo 30 de junio esta fechada una carta de Juan II que envia desde Medina al conde de Ribadeo por medio del arcediano de Cuenca, quien había salido de Roa sin problemas llevando a su vez una misiva del routier para el rey ${ }^{105}$. En su comunicación, el monarca alude al dinero que le ha mandado por medio de su sobrino Fernán Sánchez de Tovar, y que aún no ha recibido a causa de las dificultades que este ha encontrado para reunirse con su tío, y le reitera la promesa de nuevas libranzas para la satisfacción de sus servicios y de todo tipo de socorros, así como futuras recompensas. Lo más destacable de la carta real son las continuas llamadas a la lealtad y caballerosidad del routier, unos valores propios de la caballeria a los que apelaba Juan II para que continuara fiel a su persona como fasta aqui lo aueys fecho, ca esto es lo más propio del cavallero, $e$ non dando orejas ni creencia a algunos que se vos fazen o faran parientes e amigos nuevos, nin a palabras venenosas llenas de ponzoña ${ }^{106}$. De estas palabras se desprende un evidente temor al posible cambio de bando por parte del conde de Ribadeo, un sentimiento especialmente justificado si tenemos en cuenta lo efímeras que se revelaron muchas lealtades a lo largo de la guerra civil castellana. Tampoco es imposible que se hubiera producido por parte de los rebeldes alguna aproximación a Rodrigo de Villandrando con la intención de ganarse sus servicios o lograr su neutralidad, una iniciativa a la que se prestaba muy bien la situa-

104 La Crónica del Halconero recoge una carta del infante don Enrique a Rodrigo Manrique, comendador de Segura, en la que relata los acontecimientos desde Valladolid. En ella eleva a 2.200 hombres de armas las fuerzas del conde de Ledesma (ob. cit. p. 293).

105 FABIE, ob. cit., apéndice XIV, pp. 225-226.

106 Ibidem. 
ción de los ejércitos en Roa, acampados frente a frente esperando el desarrollo de los acontecimientos, pero de la que no hay constancia. Por último, en su carta Juan II muestra su satisfacción por las noticias que había recibido en la misiva del conde de Ribadeo y que sin duda habría glosado Juan Carrillo, de resultas de las cuales el monarca habría quedado convencido de la preparación y efectividad de los mercenarios franceses.

La presencia de unas importantes y escogidas fuerzas en el reino, la victoria conseguida en Roa y la situación en que quedaba la Liga nobiliaria tras el incremento cuantitativo y cualitativo experimentado por el ejército de Juan II, sin duda animaron a Álvaro de Luna a intentar sacar provecho de la situación, por lo que se dispuso a provocar un enfrentamiento en campo abierto que le permitiera acabar definitivamente con la oposición. En consecuencia, el Rey y el Condestable al frente del Ejército real, compuesto de tres mil lanzas, salieron de Medina en dirección a Olmedo con la intención de reunirse con las tropas de Rodrigo de Villandrando. Esta maniobra alteraba radicalmente la situación ya que las fuerzas nobiliarias desplegadas ante Roa corrían el riego de verse atrapadas entre dos enemigos muy superiores. Así mismo, era evidente la opción militar por la que se habian inclinado Juan II y el Condestable para revolver el conflicto, abandonando las conversaciones dada la superioridad que les proporcionaba el apoyo de las tropas de Villandrando. Sin embargo, para alcanzar el triunfo era necesario mantener la neutralidad de Juan de Navarra, más que por su importancia militar, por su significación política.

Las noticias que llegaban a las filas nobiliarias eran alarmantes. Según estas, Juan II y Álvaro de Luna al frente del Ejército real habian llegado a Peñafiel, acudiendo en ayuda del Conde de Ribadeo. Ante la posibilidad de tener que hacer frente a unas fuerzas más numerosas, el conde de Ledesma y el Almirante Enríquez levantaron el campo y se retiraron a Valladolid, junto al resto de las tropas de la Liga. Parecía que la unión entre los dos ejércitos se iba a consumar y que la intervención de Villandrando y sus mercenarios en el conflicto civil castellano iba a ser casi tan importante como el papel jugado por las compañías de Du Guesclin en 1369 , lo cual era probablemente la secreta y última aspiración del aventurero castellano. Ante el cariz que estaban tomando los acontecimientos, Juan de Navarra, temeroso de que se repitiera lo ocurrido en 1430, cuando la victoria del Condestable aparejó el despojo patrimonial de los Infantes y su derrota política, y preocupado ante las consecuencias del previsible triunfo de los realistas, decide abandonar su neutralidad. El rey de Navarra, tras contemplar el firme avance del Ejército realista en dirección a Olmedo, se percató de las repercusiones que supondría su unión con los franceses de Roa, por lo que decidió impedir 
que se produjera una batalla que pudiera traer consigo el triunfo de Álvaro de Luna, quien se quedaría sin oposición, pasándose a la Liga nobiliaria ${ }^{107}$. Esta iniciativa compensaba el desequilibrio que había traído consigo en favor del bando realista la llegada del conde de Ribadeo. Razones políticas antes que militares daban un vuelco a la situación y anulaban los efectos del concurso de los mercenarios. De esta forma, sin enfrentamiento alguno, se producía la paradoja de la derrota del Condestable y los realistas, precisamente el único bando que había alcanzado lo más aproximado a una victoria militar, lo que revela el carácter secundario que poseían los aspectos bélicos en este conflicto y la imposibilidad de resolverlo recurriendo a medios militares. Una vez más se reanudaron las negociaciones, estipulándose en el llamado Seguro de Tordesillas que para el buen desarrollo de las mismas, el conde de Ribadeo debía permanecer con sus tropas en Roa hasta su finalización para posteriormente, en un plazo de cincuenta días, abandonar el reino ${ }^{108}$. Hasta que no fueron ajustados los diferentes aspectos del Convenio de Castronuño, los grandes no permitieron que Villandrando se entrevistase con Juan II en agosto de 1439, una reunión a la que debía acudir sólo con treinta cabalgaduras. Aunque según Quicherat, el conde de Ribadeo no hizo mucho caso del acuerdo ya que varias veces envió a escondidas pequeños destacamentos a Medina para reforzar al rey ${ }^{109}$, la realidad es que el final de las negociaciones impuso que Álvaro de Luna dejase la Corte en dirección a su destierro en Escalona, lo que significaba el triunfo de la Liga nobiliaria, ahora reforzada con el rey de Navarra. Las exigencias de la oligarquía señorial relativas a las tropas de Villandrando, muestra su importancia y el temor que despertaban. Así lo indican autores como Calderón Ortega ${ }^{110}$, quien señala que la presencia de las compañías en Roa eran un elemento desestabilizador que en un momento dado podía invalidar la precaria victoria política alcanzada por los grandes. En suma, en esas circunstancias era tan decisiva la aportación de los combatientes franceses del conde de Ribadeo que el triunfo nobiliario no podía considerarse tal si no se anulaba esta amenaza.

Una vez firmado el acuerdo de Castronuño, Rodrigo de Villandrando decidió permaner en Castilla por semejantes razones a las que impulsaron su regreso. En primer lugar, hay que recordar que su situación en Francia

107 SUÁREz Fernandez, Nobleza y..., p. 150.

108 Quicherat, ob. cit., p. 176 y apéndice LXXIV, pp. 323-324. FABIE, ob. cit., p. 117.

109 Ibidem.

110 Calderón Ortega, “La formación...", p. 425. 
ya no era tan grata como en épocas anteriores, mientras que, por el contrario, sus intereses y futuro en Castilla eran importantes y prometedores ${ }^{111}$. Así mismo, no es difícil pensar en la insistencia en favor de su permanencia en el reino por parte de Juan II y Álvaro de Luna, deseosos de contar sino con sus tropas, si con sus servicios y experiencia. En consecuencia, Villandrando ordenó que sus fuerzas salieran hacia Francia, siendo encomendada su dirección a Juan de Salazar, quien quedó convertido en el nuevo capitán de los écorcheurs. Tras aproximadamente dos meses de estancia en Castilla, finalizaba la intervención de los mercenarios franceses sin saqueos, batallas de importancia o asedios; esta escasa actividad militar y su presencia reducida a Roa, no impidió que tuvieran un carácter decisivo, pues incluso - como señala Quicherat ${ }^{112}$ - los mercenarios pudieron contribuir a reducir las pretensiones de los nobles en el curso de las negociaciones. Por su parte, el conde de Ribadeo consolidó e incrementó su patrimonio y rango nobiliario gracias a su expedición castellana ${ }^{113}$. En el mismo mes de agosto de 1439, recibió de Juan II cien mil maravedies de juro anuales en compensación por el gasto que había tenido en los sueldos de las tropas que había traído a Castilla, los cuales ascendian como hemos visto a 1.600 .000 maravedíes. En septiembre, como pago por los servicios prestados y para asegurarse futuras prestaciones, el monarca otorgó a Rodrigo de Villandrando la villa de Garci Muñoz, así como el alfolí de la sal de Ribadeo y una residencia en Valiadolid ${ }^{114}$. Tras las concesiones recibidas y de acuerdo con una decidida fidelidad al monarca, el conde de Ribadeo permaneció en Castilla sin sus mercenarios pero con una guardia personal de treinta caballeros al servicio de Juan II y Álvaro de Luna hasta su muerte, a finales de la década de los cuarenta.

11 FABIE, ob. cit., p. 119.

112 QUicherAT, ob. cit., p. 177.

113 Para todo lo relativo a las donaciones y recompensas recibidas por Rodrigo de Villandrando, nos remitimos a la obra de CALDERÓN ORTEGA reiteradamente citada "La formación...".

114 lbidem y "La evolución histórica...". 